\title{
Chapter 10 \\ A Methodical Framework for Climate Change-Adapted Management in Protected Areas
}

\author{
Christian Wilke and Sven Rannow
}

\subsection{Introduction}

This chapter gives practical advice and recommendations to protected area managers on how to prepare and organise the process of adaptation to climate change. It highlights topics and working steps that are essential in the process of adaptation but also need special attention and good preparation in order to be successful.

In this chapter, we present an approach for adapting protected area management to climate change based on the specific duties, tasks, and competences of protected area managers. This approach aims at helping those practitioners who have to plan, implement and review conservation strategies and measures to protect biodiversity in protected areas. The framework builds on the results of a literature review and even more substantially - on the experience gathered in the trans disciplinary project HABIT-CHANGE (see www.habit-change.eu), where the approach was developed, discussed, tested and improved as a result of the close cooperation between scientists and protected area managers. The project focused on the management of protected habitats in large protected areas like National Parks, Biosphere Reserves and Nature Parks in Central and Eastern Europe. Its main purpose was to integrate climate change issues into management planning for protected areas. This process of adaptation resulted in "Climate-Change Adapted Management Plans" (CAMPs).

\footnotetext{
C. Wilke ( $\triangle)$

Department of Landscape Architecture and Environmental Planning, Landscape Planning and Development, Technische Universität Berlin, Straße des 17. Juni, 10623 Berlin, Germany e-mail: christian.wilke@alumni.tu-berlin.de

\section{S. Rannow}

Leibniz Institute of Ecological Urban and Regional Development, Weberplatz 1, 01217 Dresden, Germany

e-mail: sven.rannow@gmx.de
} 
This framework helps to identify the response options available to managers of protected areas on a local or regional level but also emphasises the need for cooperation with stakeholders and scientists. It is applicable in all protected areas across Europe and other continents. However, this approach needs an adequate budget, as well as time and expertise. Without additional financial means that have to be provided to protected areas the adaptation of conservation management will be not feasible.

Recommendations for required adaptations at policy level targeted at planning and implementation by regional, national, and international institutions - in parallel to adaptation in protected areas - are described in Chap. 9.

The methodical approach presented in this chapter aims to answer the key questions for managers in protected areas when it comes to adaptation:

- How can management of protected areas be adapted to climate change?

- What problems and difficulties may be experienced in adapting protected area management and how can they be solved?

- How can protected area managers reduce uncertainties by managing natural resources and learning about them at the same time?

\subsection{Adaptation Requirements for Nature Conservation: Results from Literature Reviews}

Current scholarly publications provide numerous suggestions and recommendations for the adaptation of nature conservation management to climate change (e.g. Glick et al. 2011; Hansen and Hoffmann 2011; West et al. 2009). Most authors discuss general problems of conservation management (e.g. Game et al. 2011; Hannah 2003; Lovejoy and Hanna 2005; Araujo et al. 2011). Only a few address the needs and response options for protected area managers (e.g. Lawler 2009; Welch 2005; Baron et al. 2009) or offer guidelines for adaptation of protected area management (e.g. European Commission 2012; Idle and Bines 2005; Prutsch et al. 2010).

Many recommendations for adaptation in nature conservation address the policy level or regional and national scale but are not specific enough to be applied to the tasks and capabilities of protected area management at a local level. Other recommendations aim at the scientific community and do not take practical requirements of protected area management practice into consideration.

Of the few recommendations that are focused on protected area management even fewer have been tested in the field. In their review of recommendations for adaptation to climate change Heller and Zavaleta (2009) conclude that the majority of recommendations in the published journal literature lack sufficient specificity to direct immediate action to adapt conservation practice. The general recommendations given are not applicable at the level of protected area management; therefore a practice-oriented approach - as presented below - with detailed guidance for the adaptation process is needed. 


\subsection{Adaptation of Management Planning for Protected Areas}

The adaptation of protected area management to climate change requires consistent definitions and objectives for the manifold activities, strategies and practices that are part of the active management of nature conservation. Management activities affect different stakeholders or require specific data, competencies, cooperation, and strategies. Management of protected areas is limited by financial, institutional, and legal restrictions. In addition, lack of competence within relevant administrations and a limited acceptance or willingness of local stakeholders to support the goals of nature conservation hampers its implementation. These aspects define the decision-making context and need to be considered when adapting conservation management to climate change.

The adaptation of protected area management requires an evaluation and revision of existing management practices, strategies and measures described in management plans. According to the IUCN-Definition these plans should document the "management approach and goals, together with a framework for decision making, to apply in the protected area over a given period of time. [...] Plans may be more or less prescriptive, depending upon the purpose for which they are to be used and the legal requirements to be met" (Lausche 2011, p. 29). Management plans provide guidance and standards for all management decisions and for the implementation of conservation goals, and form a basis for transparent and acceptable management decisions. Management plans are usually not so detailed that they define precise and measurable objectives for all protected species and habitats in the area, but they serve as guiding documents establishing a framework for everyday management decisions.

To address the specific tasks and challenges in adaptation, management tasks in protected areas can be divided into different groups of activities and strategies, each requiring a specific set of know-how, data, skills or expertise. Based on categories suggested by The Heinz Center (2008) we divided management tasks into activities and strategies related to:

- Land and water protection and management,

- Species conservation,

- Monitoring and planning,

- Law and policy,

- Stakeholder involvement, public relations and creation of awareness,

- Knowledge and research, science and technology.

Since most management personnel in protected areas do not have experts on their staff for all of these tasks, external expertise should be acquired to ensure effective adaptation.

Not all management activities are documented in detail in management plans. Activities related to stakeholder involvement or knowledge and research are rarely defined. Nevertheless, they have to be considered in the process of adaptation. 


\subsection{Preparing for the Process of Adaptation}

Before starting the process of adapting management plans the scope and boundary conditions of the process have to be defined.

Adapting management of protected areas is a complex and time-consuming process in which different aspects and constraints have to be considered:

- Information and expertise: What kind of data is needed and where can it be obtained? What kind of know-how is necessary and who can provide it?

- Methods, models and tools: How can information and data from climate change scenarios be used and integrated into protected area management? How can one assess sensitivity and/or vulnerability? How does one deal with uncertainties? Who can one perform the modelling and impact assessment?

- Planning process and procedures: Which steps are essential? How does one structure the process? How and when should one include the public/local expertise, land users or stakeholders? How is the concept of an active adaptive management established?

Each aspect requires specific professional, technical, and methodical skills and expertise. Not all of them will be at hand within the managing authorities of protected areas. Additional funding and cooperation with external institutions and experts from national and international organisations is therefore essential.

Prutsch et al. (2010) present a set of ten generic guiding principles for good adaptation giving directions on how to successfully carry out the adaptation process:

1. Initiate adaptation, ensure commitment and management.

2. Build knowledge and awareness.

3. Identify and cooperate with relevant stakeholders.

4. Work with uncertainties.

5. Explore potential climate change impacts and vulnerabilities and identify priority concerns.

6. Explore a wide spectrum of adaptation options.

7. Prioritise adaptation options.

8. Modify existing policies, structures, and processes.

9. Avoid maladaptation.

10. Monitor and evaluate systematically.

The methodical approach presented below takes all these factors into account and applies them to the field of protected area management.

Following the recommendations of Idle and Bines (2005) the production of management plans for conservation should actively involve the managers of the area, all stakeholders using the area for various purposes (e.g. farmers, foresters, hunters) and their respective organisations and national bodies and institutions as well as scientists and local experts. The participation of different stakeholders, institutions and other administrations (agriculture, forestry, water, etc.) must be planned and organised at the beginning of the adaptation process. 
Major challenges in adapting nature conservation management originate from a lack of sufficient understanding of the complex functional relations in natural systems and from uncertainties in predicted changes or impacts due to climate change. Additionally, knowledge about the effectiveness of different management practices is usually scarce or poorly documented. A methodical adaptation approach has to deal with these uncertainties and knowledge gaps in order to foster decision making with a limited workforce and limited time and funds available at local levels (Hansen and Hoffmann 2011). External scientific input and support is essential for all protected areas but must be tailored to meet the needs and decision contexts of each area's management (see Chap. 5).

\subsection{Introducing Adaptive Management}

Management of protected areas should be based on profound knowledge about the functional and structural components, and the conservation status of species, habitats and ecosystems. It should also be based on knowledge about the effectiveness and efficiency of different management options and their impacts on the conservation status. Unfortunately, knowledge about complex natural systems like habitats and ecosystems, about the impacts of climate change on these natural systems, and about the effectiveness of different management activities is still insufficient. However, lack of knowledge or understanding, and uncertainties in projected climatic changes or in responses to these changes can be no excuse for inaction! Instead of hesitation, the concept of simultaneously managing natural systems and learning about them should be introduced in protected area management.

Adaptive Management is organised as a learning process (Williams 2011). It is an active approach that can be used to reduce uncertainties and knowledge gaps regarding actual impacts of climate change, functional changes in ecosystems and the effectiveness of different response options. Adaptive Management is one of the most recommended strategies for dealing with climate change. It "allows managers to determine systematically whether management activities are succeeding or failing to achieve objectives" (Williams et al. 2009, p. 57). A climate change adapted management plan should prepare for the implementation of Adaptive Management and guide the necessary working steps. Williams et al. (2009) offer practical guidance for the introduction in nature conservation. The concept cannot be applied at all scales and for all management tasks (Gregory et al. 2006); however, if it is carefully prepared and tailored to a well-defined management situation, it is the key to an effective conservation under changing climatic conditions.

Its main feature is the implementation of different alternative response options at the same time in conjunction with systematic monitoring of effectiveness and efficiency of those options. Impacts of future changes along with potential measures have to be monitored and evaluated as part of the management process in order to learn about the managed resource and to improve management decisions. In that way, experts in the field can reduce the uncertainty regarding possible system 
responses and gain knowledge about processes and functional relations in habitats and ecosystems. Adaptive Management is based on intensive stakeholder involvement, precise definition of (measurable) objectives and the identification of different responses which can then be tested for effectiveness.

\subsection{Working Steps to Adapt Protected Area Management to Climate Change}

All working steps described below were selected for and tested within the HABIT-CHANGE project. The choice of working steps was based on analyses of recommendations for the process in literature.

The main outcome of the recommended adaptation process is a "Climate Change Adapted Management Plan" (CAMP) covering all aspects of climate change relevant to the respective protected area and its management. A CAMP should provide rules for decision making with regard to climate impacts. It should support all management activities in a protected area, also those implemented by land users and other stakeholders. It should contain target values and thresholds indicating if and when specific management action is required and allow for evaluation of management effectiveness. A CAMP must give specific advice on how to implement the concept of "Adapted Management" including a concept for monitoring of achievements to facilitate evaluation. The CAMP must build on existing management plans - if available - and take into account current activities and should consider continuity in management. Climate change related information, objectives and management requirements should be integrated into existing plans, structures and management concepts and aim to improve them incrementally.

The objectives of a Climate Change Adapted Management Plan (CAMP) are to:

- Analyse and present information about existing and expected pressures on natural resources and about existing and projected climatic conditions in the protected area;

- Assess the impacts of climate change on biodiversity and other protected area objectives and to identify and prioritise areas and items requiring immediate action;

- Review the current management plans in the light of the expected impact and to identify objectives, strategies and measures needing adaption in order to reduce the negative impacts of climate change;

- Develop a selection of strategies and measures to be implemented in active Adaptive Management in order to maintain a good conservation status of protected habitats and to increase knowledge about ecosystems.

- Provide recommendations to successfully involve relevant stakeholders, authorities, organisations and individuals wherever this is necessary for reaching conservation goals in a protected area; 
- Establish systematic documentation of management activities, monitor results and evaluate management effectiveness in order to make the adaptation and learning process transparent and comprehensible.

The following working steps are not intended for execution in chronological order but should be planned and started simultaneously since some of the steps are longer running and others may have to be done repeatedly. The following working steps are described below:

- Definition of objectives and scope of the adaptation process

- Revision of existing management and management plan

- Data collection and inventory of available data

- Assessment of climate change and its impacts on biodiversity

- Stakeholder involvement, communication and participation

- Development of monitoring concept

- Definition of adapted management strategies and measures

\subsubsection{Working Step: Definition of Objectives and Scope of the Adaptation Process}

The guiding question of how to adapt management of a protected area to climate change must be answered specifically in order to get a clear understanding of the scope of the adaptation process. This can be accomplished by answering the following questions:

- What is the object of adaptation: management strategies and measures; objectives, monitoring concept; communication concept, management plan; zoning of protected area, etc.?

- What context has to be considered in the adaptation process: organisational structures; legal and institutional frameworks; land users and stakeholders, existing and new collaborations, incentives and subsidies etc.?

- Which data, modelling results, and methods are or can be made available for the adaptation process: climate-change scenarios; sensitivity and impact analyses; monitoring results; guidelines and checklists; results of stakeholder dialogue and consultations, etc.?

- What are the expected results of the adaptation process: for example: a new management plan; new conservation objectives; an adapted legal and institutional framework; new concepts (Adaptive Management) and strategies; new monitoring concept; institutionalised stakeholder dialogue; changed land use, etc.?

The objectives, methods, and the scope of adaptation have to be discussed and decided in cooperation with all relevant stakeholders and the results must be documented for later evaluation. 


\subsubsection{Working Step: Revision of Existing Management and Management Plan}

The adaptation of protected area management should be based on a critical revision of the effectiveness of existing management. What must be evaluated is how well a protected area succeeds in managing the area under current climatic conditions, if management objectives and targets are reached and at what cost. Guidelines for assessing protected area management effectiveness (e.g. Hockings et al. 2006; Nolte et al. 2010) can be useful for this revision.

Key questions for the revision of management are:

- What are the main pressures on biodiversity, what problems exist and what activities and measures are available or implemented for improving conservation status?

- Are sufficient data and staff available to fulfil all management tasks?

- Is the area accepted and supported by local institutions, stakeholders and land users? Which groups have the strongest influence on the status of the protected area and cause non-climatic pressures on biodiversity?

- Does the plan contain sufficient information about planned and implemented management measures for reaching a favourable conservation status of protected species and habitats?

- Does it contain information about monitoring techniques and indicators used in monitoring the development of a protected area?

Revision of the topical management activities provides important insight into the process of adaption because an adapted management plan should not only target climate-induced pressures and impacts but also cover existing pressures and problems in order to establish successful and efficient procedures.

Available conservation plans and programmes have to be checked if they are up-to-date, complete and relevant to the upcoming day-to-day management decisions. They must be updated or amended in accordance with concepts of stakeholder dialogue, systematic monitoring or Adaptive Management activities.

Reviews within the HABIT-CHANGE project revealed that most management plans are not sufficiently specific or detailed for climate adapted management. Usually, management activities within the protected areas are not all described in the plans, which are furthermore often out of date and do not contain measurable, time-bound objectives or measures. This makes it difficult to evaluate the success and effectiveness of management. None of the reviewed plans contained any information on climate change and its impacts or a comprehensive monitoring concept as a basis for evaluating management effectiveness and establishing the concept of Adaptive Management.

It was also ascertained in the project that financial resources and manpower were often insufficient for fulfilling legal obligations. This is especially true for requirements derived from EU regulation, e.g. the EU-Habitats-Directive. Specific 
management plans for areas established under the EU-Habitats-Directive were not available in any of the areas HABIT-CHANGE investigated, although the directive came into effect over twenty years ago.

\subsubsection{Working Step: Data Collection and Inventory of Available Data}

An inventory of available data and maps for the adaptation process should be compiled very early in the adaptation process to enable the identification of gaps in the data and missing information. Up-to-date data about species, habitat distribution and conservation status, soil, water and land uses, as well as data about observed impacts of climate change are considered essential for the process of adaptation. The questions "How much data do we need to support decisions?" and "How can we provide relevant information?" must be discussed in detail before starting extensive data collection. Otherwise the process may be overloaded with data irrelevant to the planning effort.

Existing data must be evaluated with regard to how complete and up-to-date it is. For the introduction of Adaptive Management, monitoring data and information about applicable indicators are of particular relevance. Special attention should be paid to information on observed changes in biodiversity, species composition and habitat quality in comparison with historical data.

Information about past and current conflicts with stakeholders, existing pressures on protected habitats and species, as well as evaluation data regarding management effectiveness are also other important sources for the adaptation process.

\subsubsection{Working Step: Assessment of Climate Change and Its Impacts on Biodiversity}

Hardly any protected area is sufficiently equipped for carrying out assessments of climate change and its impact. Cooperation with research institutions or other scientific support is essential for obtaining relevant information. Before models are used, protected area managers have to decide what kind of results they need for management decisions (see Chap. 5). For example, data on annual, seasonal or monthly temperature changes may be less relevant than data about precipitation changes, late frosts or heavy rain. It has to be ensured that the results really fit the needs and situation of the protected area and that they help to identify possible response options such as management and mitigation measures. The time frame and reference period for models should be selected with regard to regional or national scenarios and with regard to adaptation planning results of use to important 
stakeholders like water-boards, agriculture or forestry. When using climate models it should also be taken into account that for example, projections about future temperature changes are more certain than projections about precipitation changes or extreme events. For more intensive discussion of climate projections and an overview on the currently available climate data for Central Europe see Chap. 2.

To identify impacts of climate change on a protected area and its natural assets a sensitivity analysis and an impact assessment need to accompany the modelling. Many different models are available and to date no standardised method for modelling of ecological or even social responses to climate change can be recommended without reservation. In most cases, selection of models used for sensitivity and impact analysis is strongly guided by the know-how of available scientific institutions and data. Hence, there needs to be a wholehearted discussion regarding whether or not proposed modelling results specifically address the management decisions at hand (see also Chap. 5). A special challenge is the definition of elements of the ecological or socio-ecological system that may be affected by climate change and therefore should be analysed. In some cases protected area management might be able to limit modelling of sensitivity and impact analysis to a few habitats or species because the results can easily be transferred to other parts of the area. In other cases, however, more complex and integrated modelling of all relevant features is needed (e.g. due to heterogeneous spatial conditions in the protected area).

\subsubsection{Working Step: Stakeholder Involvement, Communication and Participation}

Many conflicts in protected areas are caused by land-users and other stakeholders not accepting the objectives and measures of nature conservation because they stand contrary to their interests. It is essential to include and integrate those stakeholders and land users in the process of adaptation. This is vital for the increase of acceptance and to find win-win-solutions that help all parties involved to adapt to climate change. To foster stakeholder involvement existing conflicts and problems with land-users and stakeholders have to be analysed and documented, and suitable strategies for participation and communication must be identified.

Furthermore, land-users and other stakeholders will also have to adapt to climate change (for example, artificial irrigation to avoid drought, or snow cannons to extend tourist seasons). Such autonomous adaptation activities might not even be directly attributed to climate change. However, they can be in conflict with protection efforts, increase existing problems or even create new threats to conservation goals. Hence, the autonomous adaptation of stakeholders should be monitored and guided by conservation management.

Successful adaptation to climate change requires the close cooperation of diverse stakeholders, land-users, administrators, and scientists. Each of the 
stakeholders needs different services and should be involved at different stages of the adaption process. Hence, it is essential to tailor recommendations to the needs of the different stakeholders and make their roles in the process explicit.

In organising professional and effective stakeholder involvement special qualifications and competences are required. External expertise and support from mediators may help to organise the participation process and to overcome deadlocked conflicts. The process of stakeholder involvement is time-consuming and should be started early in the adaptation process.

\subsubsection{Working Step: Development of Monitoring Concept}

Effective management requires permanent control and evaluation of implemented measures and their impacts. Sustainable resource allocation is only possible if management effectiveness is frequently monitored. Monitoring concepts have to cover indicators for the evaluation of management effectiveness but also indicators to track status changes in important natural resources like species, habitats, biotic and abiotic conditions. Status indicators should be standardised on regional and national levels to allow tracking of changes across a wider region. Developing a monitoring concept should include a concept for data management and for data exchange and storage, in order that monitoring data can be used and evaluated by different scientific or conservation institutions and at local, regional or national levels. Systematic monitoring is the basis for the identification of local effects of climate change, but it is also essential for the obligatory review and revision of management practices in the concept of Adaptive Management.

All monitoring activities should be coordinated with regional and national institutions and monitoring tasks should be shared according to the resources and competences of the institutions involved. Protected areas cannot carry out complete climate change monitoring on their own. External support and delegation of monitoring tasks is essential. Monitoring directed and implemented by protected area staff should focus on measuring effectiveness and impact of management activities.

\subsubsection{Working Step: Definition of Adapted Management Strategies and Measures}

Management activities that are adapted to climate change are based on management strategies and measures aiming to obtain a favourable conservation status under current climatic conditions. Experience from HABIT-CHANGE shows that most current management measures are expected to be effective even under changing climate, but they have to be supported by additional measures or slightly modified (for example by changing the intensity, frequency or timing of measures). The most 
promising or effective measures should be selected and tested based on the concepts of Adaptive Management. Different management options should be implemented, monitored and evaluated under controlled conditions.

One of the most promising strategies for climate change adaptation is to strengthen the resilience of natural systems by reducing non-climatic pressures from land-use, land-use changes, fertilisation, traffic, recreational activities, etc. A wide set of management activities focusing on the alleviation of existing pressures is well known and has already been implemented. In many cases such activities need to be intensified due to the additional pressure of climate change.

The advantage of such a strategy is that it can be started immediately and that it will already be effective under current climatic conditions. However, this strategy requires profound knowledge about management effectiveness and a sufficiently equipped area management team.

\subsection{Lessons Learned from Adaptation of Management Plans in HABIT-CHANGE}

In HABIT-CHANGE the adaptation process was tested in six investigation areas and discussed with several conservation managers in Central and Eastern Europe. Experience showed that the process of adaptation needs to be tailored in a sitespecific manner to meet the needs of each protected area. There is no simple solution or general approach beyond the recommended working steps. Many decisions relevant for an effective adaptation are not solely in the hands of conservation administrators. The process of adaptation depends on local expertise and intensive communication with relevant stakeholders who may shape and design tasks and processes in a way very specific to the site. Important stakeholders need to be included, convinced and motivated to act. Local adaptation processes should be supported and partly coordinated by regional and national policies, programmes and guidance. Also the provision of funds and resources for the climate adaptation of management in protected areas has to be ensured. Many strategies have to be prepared at the national or regional level, before they can be applied at a local level. This is especially true for monitoring tasks, for modelling and assessment and for the legal framework as well as for institutional competencies and structures that cannot be implemented at or initiated from the protected area level.

From the HABIT-CHANGE project it was apparent that providing checklists and guideline documents can be helpful in supporting protected area managers, but it takes more than guidelines to initiate and maintain the adaptation process. It must be accompanied by intensive consultations with experts and it has to be tailored to the specific and individual situation of each protected area. In most cases, protected area management is not sufficiently equipped for gathering and analysing relevant data or information on its own, due to limited resources. 
In consequence, a useful approach for climate change adapted management in protected areas is one in which there is a flexible framework that defines essential working steps but leaves enough freedom for tailoring specific adaptation processes to the site-specific needs.

At the start of HABIT-CHANGE major obstacles for implementation of climate change adapted management were identified, which included:

- Missing or outdated data;

- Lack of support for climate adaptation (even within the administration of the protected area);

- Uncertainties related to modelling results on climate change and its impacts;

- Missing resources, manpower or expertise within the protected areas;

- Missing methodical approaches for incorporating modelling output, scenarios and assessment results into management plans;

- Established management "habits" that conflict with the systematic learning process required by Adaptive Management.

However, within the project's lifetime the consortium was able to overcome these obstacles and gain missing data by biotope mapping and analyses of remote sensing data; to gain support by sustained communication and awareness raising; to reduce uncertainties by using an ensemble approach for climate scenarios (see Chap. 2); to make up missing resources by obtaining external support from project partners and by providing detailed step-by-step guidance for all working steps within the methodical approach. Future steps for the implementation of climate change adapted management plans will show if established management habits will change towards a systematic learning process.

Adaptation to climate change has to be considered a continuous process as knowledge about climate change, its impacts and the effectiveness of management grows. Adaptive Management is a promising concept for gaining new knowledge and adjusting conservation efforts to changing conditions. This requires that management plans are revised and updated on a regular basis (e.g. every 5-7 years) to ensure the application of suitable adaptation strategies and measures. However, it is uncertain if all conservation goals can be maintained and harmonised with the ever-increasing need for evaluation and realignment of conservation work. Only if all potential management options fail should a discussion on changing or giving up objectives be started.

Open Access This chapter is distributed under the terms of the Creative Commons Attribution Noncommercial License, which permits any noncommercial use, distribution, and reproduction in any medium, provided the original author(s) and source are credited.

\section{References}

Araujo, M., Alagador, D., Cabeza, M., Nogues-Bravo, D., \& Thuiller, W. (2011). Climate change threatens European conservation areas. Ecology Letters, 14, 484-492.

Baron, J., Gunderson, L., Allen, C. D., Fleishman, E., McKenzie, D., Meyerson, L. A., Oropeza, J., \& Stephenson, N. (2009). Options for national parks and reserves for adapting to climate change. Environmental Management, 44(6), 1033-1042. doi:10.1007/s00267-009-9296-6. 
European Commission. (2012). Draft guidelines on climate change and Natura 2000 - Dealing with the impact of climate change on the management of the Natura 2000 Network. Luxembourg.

Game, E. T., Lipsett-Moore, G., Saxon, E., Peterson, N., \& Sheppard, S. (2011). Incorporating climate change adaptation into national conservation assessments. Global Change Biology, 2011, 17.3150-3160. doi:10.1111/j.1365-2486.2011.02457.x.

Glick, P., Stein, B. A., \& Edelson, N. A. (Eds.). (2011). Scanning the conservation horizon: A guide to climate change vulnerability assessment. Washington, DC: National Wildlife Federation.

Gregory, R., Ohlson, D., \& Arvai, J. (2006). Deconstructing adaptive management: Criteria for applications to environmental management. Ecological Applications, 16(6), 2411-2425.

Hannah, L. (2003). Impact assessments regional biodiversity impact assessments for climate change: Guide for protected area managers. In: Hansen, L., Biringer, J. L., \& Hoffman, J. (Eds.), Buying time: A user's manual for building resistance and resilience to climate change in natural systems. WWF Climate Change Programm: Berlin (pp. 235-244).

Hansen, L., \& Hoffmann, J. (2011). Climate savvy - adapting conservation and resource management to a changing world. Washington, DC: Island Press.

Heller, N. E., \& Zavaleta, E. S. (2009). Biodiversity management in the face of climate change: A review of 22 years of recommendations. Biological Conservation, 142, 14-32.

Hockings, M., Stolton, S., Leverington, F., Dudley, N., \& Courrau, J. (2006). Evaluating effectiveness: A framework for assessing management effectiveness of protected areas (2nd ed.). Gland/Cambridge: IUCN.

Idle, E. T., Bines, T. J. H. (2005). Management planning for protected areas, a guide for practitioners and their bosses. Eurosite.

Lausche, B. (2011). Guidelines for protected areas legislation (IUCN environmental policy and law paper). Gland: International Union for Conservation of Nature and Natural Resources.

Lawler, J. (2009). Climate change adaptation strategies for resource management and conservation planning. Annals of the New Yorker Academy of Science, 1162, 79-98.

Lovejoy, T. E., \& Hanna, L. (2005). Climate change and biodiversity. New Haven/London: Yale University Press.

Nolte, C., Leverington, F., Kettner, A., Marr, M., Nielsen, G., Bomhard, B., Stolton, S., StollKleemann, S., \& Hockings, M. (2010). Protected area management effectiveness assessments in Europe - A review of application, methods and results. BfN-Skripte 271a Bonn Bundesamt für Naturschutz.

Prutsch, A., Grothmann, T., Schauser, A., Otto, S., \& McCallum, S. (2010). Guiding principles for adaptation to climate change in Europe. ETC/ACC Technical Paper. European Topic Centre on Air and Climate Change.

The Heinz Center. (2008). Strategies for managing the effects of climate change on wildlife and ecosystems. Washington, DC : The H. John Heinz III Center For Science, Economics and the Environment.

Welch, D. (2005). What should protected areas managers do in the face of climate change? The George Wright Forum, 22(1), 75-93.

West, J. M., Julius, S. H., Kareiva, P., Enquist, C., Lawler, J. J., Petersen, B., Johnson, A. E., \& Shaw, M. R. (2009). U.S. natural resources and climate change: Concepts and approaches for management adaptation. Environmental Management, 44, 1001-1021.

Williams, B. (2011). Adaptive management of natural resources - framework and issues. Journal of Environmental Management, 92(5), 1346-1356.

Williams, B. K., Szaro, R. C., \& Shapiro, C. D. (2009). Adaptive management. Technical Guide. The U.S. Department of the Interior. 